\title{
ENSINO, PESQUISA E EXTENSÃO UNIVERSITÁRIA: A INDISSOCIABILIDADE DESSA TRÍADE COMO MÉTODO NA FORMAÇÃO DO BACHAREL EM DIREITO
}

\section{UNIVERSITY TEACHING, RESEARCH AND EXTENSION: THE INSEPARABILITY OF THIS TRIAD AS A METHOD IN THE GRADUATION OF THE BACHELOR OF LAW}

Joyce Ellen Pereira Barbosa

\section{RESUMO}

O presente estudo tem como objetivo analisar a função da universidade no que diz respeito à construção do conhecimento jurídico; destacar a importância das ações realizadas por meio do ensino, da pesquisa e extensão, uma vez que a universidade é fundamental para a construção de uma sociedade mais igualitária e atenta aos fatos coletivos - pensamento esse que vai na contramão do que acreditavam, anos atrás, ser a competência do sistema educacional superior. Além disso, almeja-se analisar a materialização dessas atividades e suas contribuições na formação do senso crítico dos estudantes de Direito. Em relação ao procedimento metodológico, a pesquisa trata-se de uma revisão de literatura, fundamentada no método dedutivo, partindo de uma abordagem geral para uma mais específica. A partir das discussões teóricas, é possível reconhecer a importância do trabalho conjunto entre esses três eixos, sempre confrontando a teoria com a prática e a prática com a teoria. No entanto, conclui-se que é por meio do incentivo a essas atividades construindo estratégias para fomentar o desenvolvimento dentro das faculdades jurídicas -, e da vinculação entre elas de forma efetiva, que será possível formar profissionais de Direito aptos a exercerem suas atividades.

Palavras-chave: Indissociabilidade. Ensino, pesquisa e extensão. Conhecimento jurídico. Ensino Superior no Brasil.

\section{ABSTRACT}

This study aims to analyze the role of the university with regard to the construction of legal knowledge; to highlight the importance of the actions carried out through teaching, research and extension, since the university is fundamental for the construction of a more egalitarian and attentive to collective facts society $-\mathrm{a}$ thought that goes against what it was believed, years ago, to be the competence of the University education system. In addition, it aims to analyze the materialization of these activities and their contributions to the formation of the critical sense in law students. Regarding the methodological procedure, the research is a literature review, based on the deductive method, starting from a general approach to a more specific one. From the theoretical discussions, it is possible to recognize the importance of the intertwined work between these three pillars, always confronting theory with practice and practice with theory. However, concludes that 
it is by encouraging these activities - building strategies to foster development within Law Faculties - and by effectively linking them, that it will be possible to train law professionals able to exercise their jobs.

Keywords: Inseparability. Teaching, research and extension. Legal knowledge. Brazilian University education.

\section{INTRODUÇÃO}

Frente à rapidez com a qual o ser humano absorve e transmite conhecimento, seria insustentável prosseguir com uma metodologia na qual os estudantes se mantivessem na posição de ouvintes inertes, alimentando-se apenas dos conceitos rígidos apresentados por um professor. Por isso, diante da necessidade de desenvolver o senso crítico e jurídico dos estudantes de Direito e em contrapartida a esse método de ensino tradicional, surge o ideal de incentivo ao ensino, à pesquisa e à extensão nos cursos de bacharelado em Direito, como uma forma de influenciar os estudantes a construírem seu próprio conhecimento.

Nessa perspectiva, a Constituição Federal de 1988 estabeleceu, em seu art. 207, o seguinte: “As universidades gozam de autonomia didático-científica, administrativa e de gestão financeira e patrimonial, e obedecerão ao princípio de indissociabilidade entre ensino, pesquisa e extensão".

O dispositivo constitucional supracitado trouxe, para a Educação Superior, a exigência de inserir o ensino, a pesquisa e a extensão como pilares fundamentais e obrigatórios na formação dos estudantes. Com essa medida, buscou-se diminuir o caráter dogmático das graduações, tornando o ambiente universitário mais questionador, de modo que o senso crítico dos acadêmicos passasse a ser bastante estimulado, e mais participativo em questões sociais, haja vista a praticidade e materialidade das atividades de extensão.

Tendo como princípio inspirador as abordagens acima, o presente estudo busca analisar a importância dessas três atividades no que diz respeito ao desenvolvimento acadêmico dos alunos, além de promover a indissociabilidade desses pilares que sustentam as instituições de ensino superior e são funções essenciais das universidades na formação de um profissional competente.

Por este trabalho ter como método procedimental a revisão de literatura, foram utilizados como base e parâmetro os dispositivos relevantes à matéria presentes na Constituição da República Federativa, além da legislação específica pátria e artigos científicos referentes ao tema, publicados em banco de dados oficiais.

\section{A UNIVERSIDADE E SUA CONTRIBUIÇÃO NA FORMAÇÃO DO SABER CRÍTICO DOS ESTUDANTES DE DIREITO}

Ao longo do tempo, o estudo do Direito foi se dinamizando, e o que antes era visto como unívoco e incontestável passou a ser discutido. Devido a essa univocidade, os estudantes acostumados com o ensino conservador e fragmentado, demonstram certa resistência a essas metodologias de pesquisa e extensão, sendo necessário mostrar ao discente a importância da investigação para a vida do cidadão, universidade e sociedade (LAMPERT, 2008). 
De acordo Herrera Gonzáles (1986, apud LAMPERT, 2008, p. 133), “a universidade não somente prepara para a vida profissional, mas também tem como missão a investigação, a busca de novas técnicas, novos produtos e novas aplicações”. Fundamentada nesses objetivos, torna-se imprescindível a efetivação das atividades de ensino, pesquisa e extensão nas universidades, visto que elas melhoram a vida em sociedade, abrem novas possibilidades, novos horizontes, descobertas, caminhos e trocas de conhecimento, além de propiciar aos estudantes um ensino de maior qualidade (LAMPERT, 2008).

Por fazer parte do processo educativo, o princípio científico está inserido no art. 207 da Constituição Federal de 1988, o qual se refere à essas atividades como uma tríade, o sustentáculo triplo-facetado ensinopesquisa-extensão. Nesse diapasão, o ensino e a extensão são vistos como meios de redirecionar o ensino superior para a modernidade. Já a pesquisa, como um diálogo crítico e criativo com a "realidade", na busca idealística pela verdade (ALMEIDA, 2006).

Ademais, de acordo com Lampert (2008), o ensino por meio da pesquisa é uma das opções metodológicas da qual o professor poderá utilizar para redimensionar o processo de ensino, uma vez que é capaz de envolver professor e aluno com os sujeitos do processo e não com objetos. Quando se realiza uma comparação histórica, é possível visualizar que o sistema educacional brasileiro foi e é competente para formar profissionais apolíticos, não preocupados com a sociedade - o que é, por conseguinte, um resultado indesejado hodiernamente.

É válido salientar que, com base na fundamentação acima, essas atividades demonstraram e ainda demonstram certa dificuldade de serem desenvolvidas, apesar de suas contribuições e da exigência de inclusão nos cursos de Direito, a partir da Portaria n ${ }^{\circ} 1886 / 1994$, que afirma, em seu art. $3^{\circ}$, que

O curso jurídico desenvolverá atividades de ensino, pesquisa e extensão interligadas e obrigatórias, segundo programação e distribuição aprovadas pela própria Instituição de Ensino Superior, de forma a atender às necessidades de formação fundamental, sóciopolítica, técnico-jurídica e prática do bacharel em Direito.

Essas mudanças nas diretrizes curriculares dos cursos de graduação em Direito após a Portaria Ministerial 1886/1994 demonstraram a necessidade de implantação da pesquisa, tendo como objetivo estimular o acadêmico à investigação, aliado ao debate, à argumentação e ao trabalho em equipe, contribuindo com a produção de conhecimento (ALMEIDA, 2006).

Nesse sentido, a compreensão sobre a indissociabilidade entre essas atividades, de acordo com Rays (2003, p. 73, apud CESAR, 2013), é tido como um processo multifacetado de relações que busca a unidade da teoria e prática, pois se constitui princípio das atividades fins da universidade atual.Isto é, "o sentido da indissociabilidade entre ensino, pesquisa e extensão são de inseparabilidade, haja vista, que essa tríade constitui o eixo fundamental e não pode ser compartimentado" (CESAR, 2013).

Uma análise importante acerca da tríade (ensino-pesquisa-extensão) feita por Demos (2004, p. 127 139, apud ALMEIDA, 2006) à pesquisa afirma que ela acolhe, com a mesma importância, a teoria e prática, 
desde que se trate de dialogar com a realidade e, a depender do processo, um pode ter mais destaque que o outro, mas como um processo completo exige a necessidade de confrontar a teoria com a prática, em toda prática é necessário retornar à teoria.

Tendo em vista a importância da troca de conhecimento e comunicação entre essas três atividades para a formação acadêmica, é possível notar que a extensão vinculada à pesquisa é fonte de oportunidades, da qual deriva novos espaços de aprendizagem, contribuindo com a formação do acadêmico em Direito. Desse modo, essas atividades podem ser conceituadas como um projeto educacional das universidades e que visa uma formação mais ampla, interdisciplinar, caracterizada pela transmissão de cultura, possibilitando o contato do estudante com as diversas áreas do conhecimento, para logo após ou concomitantemente avançar em sua formação profissional e técnica(LAMPERT, 2008).

Dessa forma, o desenvolvimento da pesquisa no ensino jurídico pode ser feita através da análise e interpretação das leis, controvérsias jurisprudenciais e doutrinárias. Logo, a extensão irá trabalhar o caso concreto, trazendo todo o aprendizado adquirido pelo ensino e pesquisa para o plano prático, levando em consideração a sociedade em que vive e não deixando de fora a visão globalizada de mundo (ALMEIDA, 2006).

Segundo Jenize (2004, apud RODRIGUES et al, 2013, p.145):

Os princípios da integração ensino-pesquisa, teoria e prática que embasam a concepção de extensão como função acadêmica da universidade revela um novo pensar e fazer, que se consubstancia em uma postura de organização e intervenção na realidade, em que a comunidade deixa de ser passiva no recebimento das informações/conhecimentos transmitidos pela universidade e passa a ser, participativa, crítica e construtora dos possíveis modos de organização e cidadania.

De acordo com o pensamento da autora, a extensão interfere na realidade da comunidade que recebe os conhecimentos e informações, permitindo que a universidade intervenha e contribua com suas atividades, mudando de polo. Deixa, por conseguinte, de ser passiva, ou seja, torna-se não mais aquela que apenas recebe e não participa. Adquire, então, natureza ativa (RODRIGUES et al, 2013).

Ademais, os projetos de extensão contribuem com a formação do estudante, haja vista que ele se torna mais propício a enxergar a realidade com um olhar mais crítico e sobre diversos ângulos, além de encarar a sociedade em geral como um fator importante no processo de formação acadêmica.

Diante disso, é necessário destacar que a interação ensino-pesquisa-extensão é caracterizada como um pilar que fundamenta a formação profissional do acadêmico de Direito, pois esses três pilares favorecem o desenvolvimento crítico, seja por meio da produção científica na área jurídica, seja através das atividades de extensão, estas que contribuem com a resolução de questões jurídicas que afetam o meio social. 


\section{CONSIDERAÇÕES FINAIS}

Como já abordado, a extensão aliada ao ensino e à pesquisa formam um processo educativo que proporciona a interlocução de saberes e produz conhecimento como resultado do confronto com a realidade. Além disso, essa relação tem caráter interdisciplinar, o que possibilita uma reflexão a partir de uma visão integrada das várias dimensões da sociedade - algo fundamental na formação de um profissional jurídico. Por isso, é de grande relevância os debates e incentivos ao desenvolvimento dessas atividades no universo acadêmico, para que elas sejam vistas efetivamente como de competência das instituições de ensino superior.

Ademais, é fundamental saber quebrar o paradigma do ensino tradicional do Direito, haja vista que este é uma ciência social, ou seja, vive em constantes mudanças, e a "nova" sociedade pede um Direito que acompanha essas mudanças. É somente ampliando os conhecimentos, enquanto graduandos em Direito, por meio dessas ações, que vamos entender e resolver da melhor forma possível os anseios da sociedade contemporânea.

\section{REFERÊNCIAS BIBLIOGRÁFICAS}

ALMEIDA, Maria Suely Cruz de. Os trabalhos de conclusão de curso e a contribuição para a produção do conhecimento científico no ensino do direito. IN: anais do Conpedi. Manaus, 2006. p. 5.

BRASIL. Portaria $\mathbf{N}^{\circ} \mathbf{1 . 8 8 6}$, de 30 de dezembro de 1994. Disponível em: $<$ https://www.migalhas.com.br/arquivo_artigo/art20100108-03.pdf>.Acesso em 20 de jan. 2020.

CESAR, Sandro Bimbato. A Indissociabilidade ensino, pesquisa, extensão e a gestão do conhecimento: Estudo em universidade brasileira. Projetos e Dissertações em Sistemas de Informação e Gestão do Conhecimento, v. 2, n. 2, 2013.

LAMPERT, Ernâni. O ensino com pesquisa: realidade, desafios e perspectivas na universidade brasileira. Portal de periódicos UNB: Revista Linhas Críticas, v. 14, n. 26, p. 5-24, 2008.

LIMA, Aline Ferreira de et. al. A importância do ensino, pesquisa e extensão na formação profissional. IN: anais da II Jornada Ibero-Americana de pesquisa em políticas educacionais e experiências interdisciplinares na educação, 2017.

RODRIGUES, Andréia Lilian Lima et. al. Contribuições da extensão universitária na sociedade. Periódicos grupo Tiradentes: Caderno de Graduação-Ciências Humanas e Sociais-UNIT, v. 1, n. 2, p. 141$148,2013$. 